\title{
Comunicação via mídias sociais como tecnologia educacional para assistência de enfermagem aos clientes submetidos à endoscopia digestiva alta
}

Communication via social media as an educational technology of nursing assistance to clients submitted to high digestive endoscopy

La comunicación a través de las redes sociales como tecnología educativa para la assistencia de enfermería de los clientes sometidos a endoscopia alta digestiva

Maria Célia Teixeira Barbosa

ORCID: https://orcid.org/0000-0002-7490-5537 Universidade Federal do Estado do Rio de Janeiro, Brasil E-mail:celiat.barbosa@gmail.com

Ana Cristina Silva Pinto

ORCID: https://orcid.org/0000-0002-5608-2418 Universidade Federal do Estado do Rio de Janeiro, Brasil E-mail: ana.pinto@unirio.br

Laisa Figueiredo Ferreira Lós de Alcântara

ORCID: https://orcid.org/0000-0002-2435-7616 Universidade Federal do Estado do Rio de Janeiro, Brasil E-mail: dra.laisa@gmail.com Eliza Cristina Macedo

ORCID: https://orcid.org/0000-0002-7490-5537 Universidade Federal do Estado do Rio de Janeiro, Brasil E-mail: macedo.unirio@gmail.com

Vânia Maria Fernandes Teixeira

ORCID: https://orcid.org/0000-0002-0226-9404

Universidade do Estado do Rio de Janeiro, Brasil E-mail: vluteixeira@gmail.com

Leila Leontina Couto

ORCID: https://orcid.org/0000-0002-8948-5045

Universidade Federal Fluminense, Brasil E-mail: leila_leontina@hotmail.com

Vera Lúcia Freitas

ORCID: https://orcid.org/0000-0003-1324-5640 Universidade Federal do Estado do Rio de Janeiro, Brasil E-mail: vera.freitas@unirio.br

Jeniffer Lopes Rodrigues da Silva

ORCID: https://orcid.org/0000-0003-4117-6697 Universidade Federal do Estado do Rio de Janeiro, Brasil E-mail: jenny.junior13@gmail.com

Sabrina da Silva Brasil

ORCID: https://orcid.org/0000-0002-6820-3141 Universidade Federal do Estado do Rio de Janeiro, Brasil E-mail: bina.brasil@yahoo.com.br

Isabelle Christine Nunes de Carvalho

ORCID: https://orcid.org/0000-0002-9671-3907 Universidade Federal do Estado do Rio de Janeiro, Brasil E-mail: isah_cnc@hotmail.com

\begin{abstract}
Resumo
Este estudo teve como objetivos: Identificar se as informações enviadas por mídias sociais foram assimiladas pelos clientes que serão submetidos a Endoscopia Digestiva Alta (EDA); descrever as condições de preparo do paciente para a realização da EDA frente ao recebimento das informações via mídias sociais e analisar o impacto da comunicação via mídia social como tecnologia educacional à luz da Teoria de Obtenção de Metas de King. Método: Pesquisa Convergente Assistencial, realizada em um hospital federal do Rio de Janeiro, com 17 clientes em préexame de EDA. Utilizou-se a entrevista semiestruturada, seguida de discussão dialogada com cada participante. Aplicada análise temática. Resultados: Foi observada significativa adesão do paciente ao preparo para o exame após o recebimento das informações, tanto no contato telefônico quanto na mensagem via Whatzapp®, a interação entre enfermeira/paciente foi constatada durante todo o processo, corroborando com a teoria de King quando diz que os
\end{abstract}


indivíduos envolvidos em uma interação trazem ideias diferentes assim como, atitudes e percepções individuais para serem trocadas. Conclusão: Evidenciou-se que, ao repensarmos nossa prática, além de compartilharmos nossos conhecimentos assumimos responsabilidades com a nossa ação, com o usuário do nosso serviço e seu acompanhante. O enfermeiro encontra-se em posição de avaliar o que as pessoas conhecem sobre sua saúde e a forma como elas agem para mantê-la. Através do processo de interação humana, equaciona seu conhecimento científico com o SELF do cliente (pessoa, família ou coletividade) para, através da comunicação, fixarem as metas e os meios para o alcance dos objetivos.

Palavras-chave: Enfermagem; Comunicação; Aplicativos móveis; Endoscopia gastrointestinal; Tecnologia educacional.

\begin{abstract}
This study had as objectives: To identify if the information sent by social media were assimilated by the clients who will be submitted to Upper Digestive Endoscopy; describe the conditions of preparation of the patient for the performance of Upper Digestive Endoscopy when receiving information via social media and analyze the impact of communication via social media as an educational technology according to the King's Goal Achievement Theory. Method: Convergent Care Research, carried out in a federal hospital in Rio de Janeiro, with 17 clients undergoing preexamination of Upper Digestive Endoscopy. A semi-structured interview was used, followed by a dialogue with each participant. Thematic analysis applied. Results: A significant adherence of the patient to the preparation for the exam was observed after receiving the information, both in telephone contact and in the message via Whatsapp ${ }^{\circledR}$, the interaction between nurse / patient was observed throughout the process, corroborating King's theory when says that individuals involved in an interaction bring different ideas as well as individual attitudes and perceptions to be exchanged. Conclusion: It became evident that, when rethinking our practice, in addition to sharing our knowledge, we also assumed responsibility for our action, with the user of our service and his companion. The nurse is in a position to assess what people know about their health and how they act to maintain it. Through the process of human interaction, it equates its scientific knowledge with the SELF of the client (person, family or community) in order to, through communication, set the goals and the means to achieve the objectives.
\end{abstract}

Keywords: Nursing; Communication; Mobile applications; Endoscopy gastrointestinal; Educational technology.

\title{
Resumen
}

Este estudio tuvo como objetivos: Identificar si la información enviada por las redes sociales fue asimilada por los clientes que serán sometidos a Endoscopia Digestiva Superior; Describir las condiciones para preparar al paciente para la realización de la endoscopia digestiva alta al recibir información a través de las redes sociales y analizar el impacto de la comunicación a través de las redes sociales como tecnología educativa a la luz de la teoría del logro de metas de King. Método: Investigación de Cuidados Convergentes, realizada en un hospital federal de Río de janeiro, con 17 clientes sometidos a preexamen de endoscopia digestiva alta. Se utilizó una entrevista semiestructurada, seguida de un diálogo con cada participante. Análisis temático aplicado. Resultados: Se observó una adherencia significativa del paciente a la preparación para el examen luego de recibir la información, tanto en el contacto telefónico como en el mensaje vía Whatzapp ${ }^{\circledR}$, se observó la interacción entre enfermera / paciente durante todo el proceso, corroborando la teoría de King cuando dice que los individuos que participan en una interacción aportan diferentes ideas, así como actitudes y percepciones individuales para intercambiar. Conclusión: Se hizo evidente que, cuando repensamos nuestra práctica, además de compartir nuestro conocimiento, asumimos responsabilidades con nuestra acción, con el usuario de nuestro servicio y su acompañante. La enfermera está en condiciones de evaluar lo que las personas saben sobre su salud y cómo actúan para mantenerla. A través del proceso de interacción humana, equipara su conocimiento científico con el SER del cliente (persona, familia o comunidad) para, a través de la comunicación, establecer metas y los medios para lograr los objetivos.

Palabras clave: Enfermería; Comunicación; Aplicaciones móviles; Endoscopía gastrointestinal; Tecnología educacional.

\section{Introduçãa}

As mudanças econômicas, políticas, sociais e culturais que ocorreram nos últimos séculos no Brasil e no mundo, influenciaram diretamente o comportamento humano e sua relação com o ambiente, produzindo alterações significativas no processo de viver, adoecer e morrer das sociedades modernas.

A pesquisa partiu de minha experiência prévia acerca da realização do exame de endoscopia digestiva alta, em que se observava um grande número de exames cancelados ou realizados de forma ineficaz pois os clientes chegavam com muitas dúvidas a respeito desse exame e o preparo realizado de forma ineficiente. 
Ciente de toda dificuldade que o usuário do SUS enfrenta para obter atendimento, principalmente devido ao custo com deslocamentos, foi necessário pensar na comunicação à distância e em como as mídias sociais poderiam ser mediadoras desse cuidado educativo.

A Endoscopia Digestiva Alta é um método invasivo para examinar órgãos e cavidades do corpo, dependendo da tolerância do cliente pode causar um certo grau de desconforto (Silva, 2010).

Observa-se na atualidade o desenvolvimento de tecnologias cada vez mais precisas e sofisticadas no campo da saúde. E o uso das Mídias Sociais aumentou exponencialmente nos últimos anos enquanto meio facilitador nas relações interpessoais e disseminador de informações, seja no agendamento ou na orientação (Frazier et al., 2014).

Esta plataforma pode auxiliar a sanar dúvidas e o mesmo tornar-se uma rede de apoio, principalmente no contexto do preparo para o exame de endoscopia Digestiva, com o intuito de informar, orientar ou esclarecer acerca das diversas ações realizados junto a clientela assistida na área de saúde, assim teremos a tecnologia como forte aliada na busca pela melhoria no cuidado em saúde e segurança do paciente (Silva et al., 2020).

A mídia social pode ser definida como a constelação de ferramentas baseadas na Internet que ajudam um usuário a se interligar, contribuir e se comunicar com outras pessoas em tempo real, como o próprio nome indica, a mídia social cria um diálogo social ou uma conversa entre os usuários (Frazier et al., 2014).

Percebe-se que, um percentual significativo de exames deixa de ser realizado devido à falta de informação específica para a execução dos exames endoscópicos, em especial os de Endoscopia Digestiva Alta, não só a suspensão de procedimentos como também a realização do exame com um preparo ineficaz, que determinam o aumento do risco de complicações durante o procedimento.

Mostra-se a necessidade de buscar estratégias adequadas as características nesse fluxo de atendimento os quais garantam a segurança do paciente durante a realização do exame. Garantindo a informação e orientação para a clientela atendida nesses serviços onde exames diagnósticos como a endoscopia digestiva alta são realizados.

O Brasil é um dos países que mais utiliza canais digitais, tanto para obter informações médicas quanto para estabelecer contato com colegas de profissão e clientes. Um estudo brasileiro identificou que mais da metade dos médicos participante (62,5\%) relatou que usava o WhatsApp para se comunicar com seus clientes (Leão et al., 2018).

Assim mídias sociais emergem como uma estratégia promovedora para alcançar um cuidado seguro, uma situação clínica adequada ao exame prescrito ou outro procedimento solicitado durante um percurso terapêutico ambulatorial de clientes submetidos a endoscopia digestiva alta.

O Conselho Federal de Enfermagem (COFEN) respeita a liberdade de expressão dos Profissionais de Enfermagem e espera que usem as mídias sociais com responsabilidade, conscientes das oportunidades e também das consequências que seus atos podem gerar, pois reconhece os benefícios profissionais, institucionais e sociais da atuação da enfermagem nesses meios (COFEN, 2017).

O uso de Comunicações Instantâneas ou WhatsApp®, é reconhecido na literatura como um método de comunicação e esclarecimento de dúvidas em tempo real, facilitando o manejo das dificuldades associadas ao tratamento, com repercussões positivas para o alcance da adesão adequada (Lima et al., 2018).

É nesse cenário que a Teoria da Obtenção de Metas através de seus conceitos e princípios, dão suporte às relações interpessoais existentes não somente na prática da enfermagem, mas também, de outros profissionais de saúde que assistem ao cliente em preparo para exames. E segundo a teórica Imógenes King, a interação é definida como um processo de percepção e comunicação entre a pessoa e o ambiente e entre a pessoa e outra pessoa, representada por comportamentos verbais e não verbais dirigidos à obtenção das metas (King, 1981). 
Ainda segundo KING, comunicação é o processo pelo qual a informação é passada de uma pessoa para outra, tanto diretamente em um encontro face a face, quanto indiretamente através do telefone, televisão ou palavra escrita, sendo assim, é de grande importância recorrer a comunicação digital como forma de melhorar o preparo dos clientes para o procedimento como a endoscopia digestiva alta e minimizar os cancelamentos de exames.

Visto que, a comunicação digital pode ser entendida como o uso das Tecnologias Digitais de Informação e Comunicação (TIC's), e de todas as ferramentas delas decorrentes, para facilitar e dinamizar a construção de qualquer processo de Comunicação Integrada nas organizações, inclusive de saúde (Corrêa, 2009), pois o uso da tecnologia amplia o conhecimento social, sendo possível buscar informações e recursos para sua saúde e a identificação de mudanças, portanto, o enfermeiro, profissionalmente qualificado, deve desenvolver ferramentas que favoreçam a autonomia na verificação das necessidades (Thomas \& Fontana, 2020).

A interação entre as pessoas é facilitada pela comunicação, uma vez que esta deve ser entendida como um processo que compreende e compartilha as mensagens enviadas e recebidas, estabelecendo um intercâmbio entre elas e seu meio. Essa interação pode ser considerada como uma tecnologia de informação acessível a processos educacionais necessários a prática assistencial ambulatorial como a realizada em um serviço de Endoscopia Digestiva Alta, cenário do estudo (Selhorst et al., 2014).

A realização do preparo para endoscopias executado de forma eficaz é o diferencial para o diagnóstico precoce de doenças que acometem o sistema gastrointestinal. Conforme dados do INCA, estimam-se que no ano de 2020, 13.360 casos novos de câncer de estômago entre homens e 7.870 nas mulheres, das taxas brutas e ajustadas de incidência por 100 mil habitantes, entre homens, é o quarto mais incidente e o sexto entre as mulheres (INCA,2020).

Diante destes dados alarmantes é necessário alcançar esforços para melhorar a adesão do paciente na realização dos exames diagnósticos, pois um novo agendamento pode significar prejuízo diante da possibilidade de uma detecção precoce de lesões existentes (Deng et al., 2015).

Além disso, tudo o que pode afetar a segurança do paciente, desperdiçar recursos hospitalares e perturbar o cronograma de trabalho planejado, além de postergar resultados podem limitar a qualidade do cuidado oferecido.

Pelo exposto, o estudo tem por objetivos identificar se as informações enviadas por mídias sociais foram assimiladas pelos clientes que serão submetidos a EDA; descrever as condições de preparo do paciente para a realização da EDA frente ao recebimento das informações via mídias sociais e analisar o impacto da comunicação via mídia social como tecnologia educacional, à luz da Teoria de Obtenção de Metas de King.

\section{Metodologia}

O projeto de pesquisa foi submetido no Comitê de Ética da instituição proponente e aprovado sob o parecer 3.774.986 e CAAE 26137419.9.0000.5285. Trata-se de uma pesquisa qualitativa, visto que, este método refere-se à adoção de parte da visão do pesquisador sobre o fenômeno em estudo (Pereira et al.,2018), delineada a partir de Pesquisa Convergente Assistencial (PCA). Esta tem como premissa a convergência das ações de pesquisa com a da assistência, objetivando indicar ações para o cuidado de saúde, articulando as ações dos indivíduos envolvidos no contexto a ser pesquisado, em franca relação de cooperação mútua a integrar teoria e prática (Trentini et al., 2014).

Para que isso ocorra, o problema de pesquisa deve emergir da prática assistencial em que os resultados tenham como propósito a melhoria da assistência no local estudado ${ }^{14}$. Além disso, enquanto método qualitativo, a PCA busca identificar informações que apontem para o tema investigado com vistas a melhorias, as quais estão firmadas nas experiências relatadas pelos participantes da pesquisa, a partir do princípio da saturação de ideias onde "informações de um único sujeito têm o mesmo valor, como se provenientes de todos os sujeitos (Trentini et al., 2014). 
Diante do exposto e ciente de que o objetivo da PCA está em indicar ações para o cuidado de saúde, articulando as pessoas envolvidas no contexto a ser pesquisado, em uma relação de cooperação mútua, integrando a teoria com a prática, o fazer e o pensar, com a necessidade de renovar esta mesma prática (Trentini et al., 2014). Surgiu a necessidade de auto indagação na pesquisadora, a partir das seguintes indagações sugeridas por Trentini, Paim e Silva (Trentini et al., 2014): O que não está bem na prática assistencial? Quais são os problemas? O que poderia ser modificado? Que inovações poderiam ser introduzidas?

A partir destas indagações e juntamente com as questões apontadas pela equipe multiprofissional do serviço, percebi a necessidade da comunicação com os clientes antes do dia agendado para o exame. Porém, ciente de toda dificuldade que o usuário do SUS apresenta, principalmente com relação ao deslocamento até o hospital, optei pelo contato telefônico e envio de mensagens instantâneas através do aplicativo WhatsApp®.

Dois dias antes da realização do exame é feito o contato com o paciente através do telefone disponibilizado na agenda do Núcleo Interno de Regulação (NIR), o objetivo desse contato é confirmar a veracidade do número do celular antes do envio da mensagem. É perguntado se ele está ciente do exame e suas dúvidas, geralmente o paciente faz perguntas relacionadas ao preparo, são passadas todas as informações referentes ao preparo para o procedimento, respondidas as dúvidas que surgem, são reforçadas as informações referentes ao endereço do hospital, documentos que deverão ser apresentados, etc.

Neste momento é perguntado ao paciente se possui o aplicativo WhatsApp ${ }^{\circledR}$ e se o mesmo autoriza o envio deste preparo que foi informado verbalmente através do aplicativo, tendo a resposta positiva do paciente ou acompanhante, a mensagem é enviada logo após o contato, nesta mensagem consta todo o preparo para o exame, orientações para o acompanhante, e algumas informações sobre o acesso ao Serviço de Endoscopia Digestiva (SED).

Vale destacar que todas as informações referentes ao preparo, inclusive relacionadas a medicamentos enviadas através da mensagem com o objetivo de ratificar as orientações passadas na ligação telefônica, foram avaliadas por profissionais especialistas na área de endoscopia e, a ligação é realizada por uma enfermeira do serviço de endoscopia, com experiência na área e autora desta pesquisa.

Sendo assim, optou-se pelo WhatsApp Business®, pois é possível criar mensagem de ausência avisando ao paciente, caso ele entre em contato fora do horário do plantão, e informar quando eles poderão fazer novamente o contato.

Em geral o paciente utiliza o meio de comunicação para fazer perguntas as quais tem a necessidade de saber e geralmente os mesmos se sentem à vontade e perguntam, falam sobre os medos e ansiedade que este exame causa para a maioria das pessoas. Sendo assim, ao realizar o processo de comunicação com os clientes coloco-me à disposição para exercer o meu papel, corroborando com a definição de King (1981) quando diz que o papel é definido como um conjunto de comportamentos esperados de pessoas que ocupam uma posição no sistema social.

Desta forma, a pesquisadora efetua todas as orientações pertinentes ao exame e esclarece as dúvidas que surgem desta demanda, assim como solicita ao mesmo a viabilidade do envio dessas informações por WhatsApp® ${ }^{\circledR}$ com o objetivo de reiterálas e caso a resposta seja positiva faz o envio da mensagem convencionada, a qual apresenta-se na Figura a seguir: 
Figura 1 - Mensagem enviada ao cliente por WhatsApp ${ }^{\circledR}$

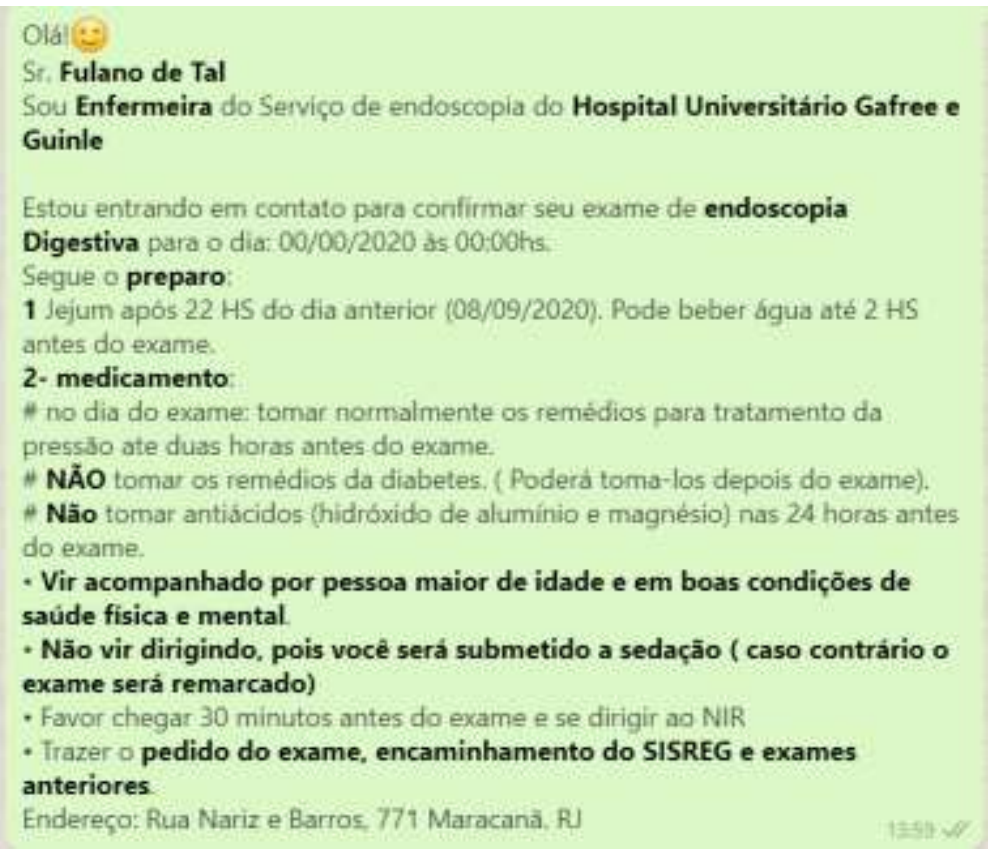

Fonte: Autores, Rio de Janeiro/RJ (2020).

Para tanto, a pesquisadora fundamentou-se na Teoria do Alcance de Metas, que entende a enfermagem como a relação interpessoal entre um paciente que necessita de ajuda e um profissional enfermeiro que pode reconhecer e responder às suas necessidades (King, 1981).

Esse tipo de relacionamento é essencial para determinar a individualidade do cliente e fazer com que participem juntos do tratamento. Busca-se construir um modo eficaz de orientar e esclarecer dúvidas relativas ao EDA, isto é, uma tecnologia educacional segura.

O estudo foi desenvolvido no ambulatório de Endoscopia Digestiva de um hospital universitário no município do Rio de Janeiro, os participantes foram 17 clientes do serviço, em pré-procedimentos de endoscopia digestiva alta que aceitaram participar do estudo e que satisfizeram os seguintes critérios de inclusão: clientes com solicitação do exame oriundos dos ambulatórios internos, marcações das agendas do Núcleo Interno de Regulação de Vagas (NIR), clientes oriundos do Sistema Nacional de Regulação (SISREG) e maiores de 18 anos que receberam as orientações por mídias sociais.

Foram excluídos do estudo: Os legalmente incapazes, portadores de deficiência visual com incapacidade para leitura e os clientes com alterações cognitivas e dificuldade para falar. Após a aplicação dos critérios de seleção, não houve recusa dos selecionados e nem perda de participantes durante o desenvolvimento da pesquisa.

A coleta de dados transcorreu no período de dezembro de 2019 a setembro de 2020, vale ressaltar que após o encontro com 10 participantes da pesquisa e um total amostral de 07 entrevistas, visto que 03 foram retiradas do estudo por fazer parte do teste piloto, a amostra precisou ser interrompida pois teve início a pandemia do COVID 19, com considerável consequência na saúde pública e na saúde mental de toda a sociedade.

Vale destacar que neste novo cenário, o de distanciamento social, tornou-se mais evidente a necessidade do contato com o paciente através de mídias sociais e a importância das tecnologias educacionais de forma segura, uma vez que os hospitais universitários, centros de formação e qualificação profissional, bem como de produção de conhecimento, têm significativo papel no enfrentamento dessa nova realidade mundial.

Após 5 meses de afastamento da pesquisa imposto pela pandemia, a mesma foi retomada, seguido o critério de saturação dos dados, com um total de 17 entrevistados. Este conceito descreve o alcance de homogeneidade nas informações 
do grupo em estudo a partir de várias perspectivas do pesquisador, ou seja, é o momento que o acréscimo de dados na pesquisa não alterará a compreensão e resultado do objeto estudado (Minayo, 2015).

Utilizou-se a técnica de entrevista individual semiestruturada, seguidas de discussão dialogada com cada participante. O diálogo iniciou-se durante a prática assistencial com a finalidade de obter informações sobre a identificação pessoal, perfil clínico e sociodemográfico para caracterizá-los.

Cada entrevista teve duração média de trinta minutos, as quais foram audiogravadas e posteriormente transcritas, respeitando o anonimato de cada participante, utilizando-se de codificação alfanumérica para a identificação de cada um. Em seguida, os dados foram analisados por intermédio de análise temática, a qual foi desenvolvida em três etapas: pré-análise; exploração do material; tratamento dos resultados, inferência e interpretação (Minayo, 2015). Dessa forma, os dados foram codificados, analisados e contextualizados com a Teoria da Obtenção de Metas de King.

\section{Resultados e Discussão}

A pesquisa foi composta por 17 clientes em pré exame de EDA. Dentre os participantes do estudo, nove $(52,9 \%)$ eram mulheres e oito $(47,1 \%)$ eram homens, dentre essas mulheres, três (17\%) estavam na faixa etária até 59 anos e seis (35\%) com 60 anos ou mais, já entre os homens dois (12\%) estavam na faixa etária até 59 anos e seis (35\%) com 60 anos ou mais.

O diálogo entre a pesquisadora e os participantes iniciou-se com a indagação de que saberes e informações os clientes que serão submetidas ao exame de EDA assimilaram após o envio por mídias sociais de material educativo?

Após análise temática das falas destacou-se três categorias temáticas: 1) Concepções e Vivências pré exame; 2) Compreensão Acerca das informações transmitidas e 3) Impacto da Orientação a Distância.

\section{Concepções e Vivências pré exame}

Essa Categoria retrata as concepções e vivências, e principalmente as opiniões dos clientes relacionadas ao exame. O conhecimento dos clientes a respeito de suas próprias patologias garante à equipe multiprofissional a excelente oportunidade para melhorar a qualidade de vida destes clientes, seja por meio do estímulo ao autocuidado, seja por meio do estímulo à adesão ao tratamento medicamentoso e não medicamentoso, ou ainda, por meio de ações que aproximem o paciente dos serviços de saúde (Pereira et al., 2014).

Nesse caso foi bem perceptível queixas relacionadas a má orientação e repasse de informação sobre a condução do exame e em grande parte dos casos, reclamações sobre a demora na realização do mesmo e até a desmarcação do exame.

\footnotetext{
[...] Ih! Muito tempo! ... não tinha me informado não, depois que a senhora ligou pra mim, foi que eu fui lá, porque o doutor falou... eles não me falaram nada! aí eu cheguei em casa a senhora me ligou aí falou negócio de exame [...] E6
}

Clientes em preparo para algum procedimento geralmente possuem sentimentos conflitantes, como é possível perceber em uma pesquisa com clientes em preparo para cirurgia. Os autores destacam que neste momento de que antecede a cirurgia, o paciente está em fase de afastamento das atividades e envolvido pelo momento, o que pode dificultar a assimilação de informações verbais fornecidas pela equipe cirúrgica (Barell et al., 2018).

Considerando isso, os discursos ainda apontam que os paciente não receberam informações importantes referente ao preparo para o exame.

[...] Sim, a respeito do jejum, eu pensei que era pra ficar de jejum o dia todo antes do exame, eu sempre fazia isso, poxa [...] E11 


\section{[...] Eu não ia tomar os remédios da pressão o médico não falou nada! [...] E8}

Um estudo com paciente sendo submetidos a endoscopia digestiva alta apontou que no desenvolvimento da entrevista após a realização do exame pode notar uma satisfação na maioria dos entrevistados, pois anteriormente, estavam preocupados, e quando eles retornaram na revisão demonstravam segurança nas respostas relacionada a expectativa após a realização do exame e, se fosse necessário realizaria novamente o procedimento (Silva, 2013).

A comprovação da falta ou inadequação de informações aos clientes e seus acompanhantes sobre todos os aspectos e etapas que envolvem a realização do exame de endoscopia é contraditório com os princípios da política nacional de humanização no que envolve a participação dos usuários e de suas redes em seu processo de Saúde Doença (Humaniza, S. U. S. 2004).

Um estudo realizado objetivando identificar o perfil e as expectativas do usuário submetido à Endoscopia Digestiva Alta, relatou que dos entrevistados, alguns mencionaram ter preferência por um trabalhador da enfermagem como a pessoa indicada para passar as orientações referentes ao procedimento (Selhorst et al., 2015).

\section{Compreensão Acercas das informações transmitidas}

Sobre essa categoria, pode-se perceber discursos referente tanto ao conhecimento sobre o exame em si, quanto ao seu preparo. Muitos clientes referiram não saber nada por não terem recebido informações, ou aqueles que receberam informações, mas não as compreenderam corretamente.

[...] Fiz jejum... não comi mais nada até agora, bebi um pouquinho de água agora... Não a da pressão eu não sabia, eles não me falavam [...] E4

[...] mas quando foi de manhã eu não sabia se poderia tomar o remédio de pressão... porque eu perdi o papel do sisreg e não consegui e o telefone da mensagem também não atende. [...] E10

\section{[...] eu não sabia até que horas eu podia comer, não sabia que o remédio de pressão podia tomar [...] E17}

Os profissionais de enfermagem na promoção da saúde estarão comprometidos a reproduzir programas, e a liderança de equipes de serviço saúde, cujos atos objetivam trabalhar para promover atividades, atitudes e condutas de saúde positivas (Pereira et al., 2018).

A educação em saúde, e troca de informações é essencial para um bom atendimento em saúde. Quando o paciente conhece o procedimento e é informado sobre o preparo seu nível de ansiedade diminui e o mesmo se sente calmo e disposto a realizar o procedimento, diminuindo a possibilidade de ocorrer intercorrências.

[...] eu entendi que tinha que fazer um preparo a partir de vinte e duas horas jejum, duas horas antes do exame sem beber água, de manhã se tivesse remédio de hipertensão pra tomar [...] E8

\section{[...] é ... não consumir nada depois das dez horas... foi tudo bem claro [...] E15}

Destaca-se que o paciente prefere ser instrumentalizado antes do exame, afinal receber informações de um profissional antes do procedimento pode trazer um grau de tranquilidade e otimismo de que tudo transcorrerá bem durante o procedimento. 
[...] Quando o médico me pediu para fazer esse exame, eu não sabia o que era, eu não ia fazer.... uma amiga falou que colocavam um tubo na garganta, eu fiquei nervosa! Por isso fiz todas as perguntas quando a enfermeira me telefonou... (risos...) [...] E9

Pesquisas apontam que uma pequena parcela dos clientes que realizaram o exame de endoscopia tinha algum conhecimento prévio sobre o procedimento, mas que se restringia a como deveriam proceder para a realização do mesmo em relação à alimentação e atestado médico para justificar a ausência ao trabalho e essas informações vieram de familiares, amigos e conversas na sala de recepção (Selhorst et al., 2015).

\section{Impacto da Orientação a Distância}

Sobre essa categoria temática o ponto de mais destaque são as opiniões positivas e em como o contato através da ligação e da mídia social impactou positivamente no aprendizado, comunicação e preparo do paciente em relação ao procedimento.

\section{[...] Ah me preparei...porque se não falasse nada né? Eu ia vim ca barriga cheia [...] E6}

[...] eu não sabia que os remédios da pressão eu podia tomar, o da diabetes eu já sabia que não podia, mas eu pensei que o da pressão também não podia. Muito boa, muito boa! [...] E9

\section{[..] Ah, foi importante né, porque você fica sabendo das coisas né? [...] E14}

[...] Eu entendi tudo direitinho a pessoa que me telefonou foi muito educada e prestativa, entendi que eu poderia jantar uma comida leve e quando fosse dez horas da noite... entendi do acompanhante... Muito boa essa ideia, isso podia ser pra tudo né? Pros outros exames também. [...] E17

A ausência de informações e/ou o não entendimento das informações fornecidas pelos profissionais da saúde aos paciente são também fatores que podem trazer consequências negativas, como a não adesão ao tratamento, favorecendo assim ao insucesso terapêutico; retardo na administração do medicamento, agravando o quadro clínico do paciente; aumento da incidência de efeitos adversos, erros no esquema de administração e/ou duração do tratamento; impedimentos na diferenciação entre manifestações da doença e efeitos adversos da terapêutica; e indução à automedicação. Bem como outras sérias decorrências, que podem piorar o estado de saúde do paciente (Pereira et al., 2018).

O profissional e o cliente devem constantemente avaliar seu progresso relacional no que se refere ao processo ensinoaprendizagem, uma vez que a mudança de comportamento do paciente constitui um importante fator para a garantia da continuidade de sua assistência.

Corroborando com a teoria de obtenção de metas de King quando diz que a prática de enfermagem é diferenciada das demais profissões ligadas a saúde devido ao que as enfermeiras fazem com e para os indivíduos, a obtenção das metas ocorre nos sistemas interpessoais, nos quais duas pessoas, que são geralmente estranhas, juntam-se em uma organização de atendimento de saúde para ajudar e receber ajuda, mantendo um estado de saúde que permite o funcionamento em seus papéis (King, 1981).

A importância das orientações da enfermagem e o impacto positivo da educação em saúde pode ser conferido nos discursos abaixo.

[...] eu não tenho experiencia no cotidiano pra dar alguma coisa de melhorar, mas comigo, o que você ligou, você mandou pelo WhatsApp e tal, foi tudo perfeito [...] E1 
[...] Pelo WhatsApp mesmo, comunicação, comunicação.... né? do jeito que foi feito foi válido sim com certeza! Pra mim foi ótimo [...] E3

[...] Esse sistema que vocês colocam passo a passo pelo WhatsApp fica muito claro... o WhatsApp vem uma explicação mais rápida, né? E com bom esclarecimento, entendimento. [...] E4

[...] Foi boa, a menina me explicou tudo direitinho, me deu informação, foi boa! [...] E12

[...] eu fiquei até surpresa porque eu nem estava esperando na verdade né? ... Ah, pra mim foi ótimo, não fiquei com dúvida de nada não, pra mim foi tudo esclarecido. [...] E15

A atuação do enfermeiro e a importância da educação em saúde ainda podem ser verificadas e confirmadas nas falas abaixo.

[...] sim eu achei que tornou tudo mais prático, mais simples... Não... eu acho que essa forma feita tá muito boa, de ligar e mandar mensagem, eu acho que é mais acessível [...] E5

[...] mas ainda bem que ela escreveu na mensagem que ela mandou, aí eu tomei todos os remédios da pressão, poxa! Ainda bem que eu li a mensagem! ... Eu avalio com nota dez! eu acho que este atendimento é o que deveria ser feito em todos os hospitais! Ajudam muito, pelo menos pra mim que sou medroso ajudou muito, eu só acho que poderia ser assim também para marcar uma consulta aqui... Que este número que me ligaram ficasse disponível pra entrar em contato [...] E10

[...] Ótimo ...né? me avisaram direitinho... nunca mais eu fico o dia todo com fome antes de fazer o exame, da última vez eu fiquei em casa sozinha para não comer nada, poxa...não precisava. [...] E11

A função de educadora possibilita ações educativas que despertem a consciência crítica dos clientes e familiares, favorece o esclarecimento de dúvidas e a redução da ansiedade a fim de alcançar o envolvimento na terapêutica proposta (Pinto et al., 2017).

As tecnologias leves, se expressam como o processo de produção da comunicação, das relações, de vínculos que conduzem ao encontro do usuário com necessidades de ações de saúde (Santos et al., 2008). E desta forma podemos dizer que através da comunicação a informação é passada de uma pessoa para outra e pode ser direta ou indiretamente, ocorrendo a interação e consequentemente a obtenção da meta, proposta por King.

Observa-se uma tecnologia educacional em construção a partir das necessidades requeridas tanto pelo paciente e familiares, bem como frente ao exame endoscópio prescrito. Um processo educacional firmado na prática assistencial segura, na orientação eficaz e no acesso proporcionado pela utilização de mídias sociais como as mensagens instantâneas, por exemplo.

\section{Considerações Finais}

Este estudo se configurou como uma pesquisa qualitativa, com delineamento na Pesquisa Convergente Assistencial. A PCA possui uma relação intencional com a prática, vinculando o pensar e agir em enfermagem, tal método permitiu a imersão da pesquisadora no campo prático ao mesmo tempo que realizava a produção de dados, atendendo aos fundamentos de imersibilidade e simultaneidade da PCA, no mesmo espaço físico e temporal.

O propósito global das enfermeiras é promover a saúde, prevenir a doença e se preocupar com o doente, diante disso, equacionou-se a teoria de obtenção de metas de Imógenes King pois o objetivo dessa teoria é ajudar os indivíduos a manter um estado saudável e, assim, ajudá-los a desempenhar suas funções na sociedade. 
O enfermeiro encontra-se em posição de avaliar o que as pessoas conhecem sobre sua saúde e a forma como elas agem para mantê-la. Através do processo de interação humana, equaciona seu conhecimento científico com o SELF do paciente (pessoa, família ou coletividade) para, através da comunicação, fixarem as metas e os meios para o alcance dos objetivos.

As Mídias Sociais representam instrumentos que podem auxiliar no processo de educação em saúde desse público. Ressalta-se que para que este processo seja eficaz é importante que estas ferramentas sejam atrativas e interativas e que por meio delas sejam disponibilizadas informações de qualidade sobre saúde.

Também não podemos esquecer que o uso dessas tecnologias deve ser pautado na ética e respeito ao usuário, assim como não a substituir ao contato real, de forma segura devido ao momento de pandemia em que vivemos, mostra-se uma ferramenta oportuna e acessível.

Faz-se necessário que profissionais da saúde reconheçam a potencialidade das Tecnologias da Informação e Comunicação e desvelem as inúmeras possibilidades de uso destas ferramentas como estratégia de alcance, Para tanto, é relevante que tais ferramentas sejam desenvolvidas e aplicadas objetivando não apenas a disponibilização de conteúdos, mas propiciando a construção compartilhada de conhecimentos por meio de mecanismos que permitam o diálogo virtual com os usuários, desenvolvendo, desse modo, o pensar crítico e construtivo do educando.

Considerando as lacunas do conhecimento identificadas na revisão integrativa, assim como os resultados encontrados no presente estudo foi possível observar como é importante atender ao paciente de forma a respeitar as suas limitações e oferecer um atendimento pautado na segurança no cuidado de maneira individualizada, não esquecendo da sua autonomia.

Desse modo, espero que essa pesquisa possa contribuir na construção de conhecimento com vista a construção de tecnologia educacional e melhoria da assistência ao paciente que será submetido ao exame de endoscopia digestiva alta - EDA.

Como sugestão, os estudos futuros poderão aproximar-se com maior destaque ao uso do aplicativo WhatsApp na prática de educação em saúde, visto que, a comunicação online tem ganhado espaço, sendo quase inevitável que influencie cada vez mais a prática dos profissionais de saúde.

\section{Referências}

BarelI, P. S., Sousa, C. S., PovedaI, V. B., \& TurriniI, R. N. T. (2018). Ansiedade e conhecimento de clientes submetidos a cirurgia ortognática no préoperatório. Revista Brasileira de Enfermagem, 71, 2206-2211.

Conselho Federal de Enfermagem (COFEN). Resolução no 554, de 17 de julho de 2017. Dispõe sobre estabelecer os critérios norteadores das práticas de uso e de comportamento dos profissionais de enfermagem, em meio de comunicação de massa, na mídia impressa, em peças publicitárias, de mobiliário u [Internet].2017. http://www.cofen.gov.br/resolucao-cofen-no-05542017_53838.html

Corrêa, E. S. (2009). A Comunicação Digital nas organizações: tendências e transformações. Organicom, 6(10-11), 161-167.

Deng, X., Wang, Y., Zhu, T., Zhang, W., Yin, Y., \& Ye, L. (2015). Short message service (SMS) can enhance compliance and reduce cancellations in a sedation gastrointestinal endoscopy center: a prospective randomized controlled trial. Journal of medicais systems, 39(1), 1-11.

Souza Minayo, M. C. (2017). Amostragem e saturação em pesquisa qualitativa: consensos e controvérsias. Revista pesquisa qualitativa, 5(7), 1-12.

Frazier, B., Culley, J. M., Hein, L. C., Williams, A., \& Tavakoli, A. S. (2014). Social networking policies in nursing education. CIN: Computers, Informatics, Nursing, 32(3), 110-117.http://www.scielo.br/scielo.php?script=sci_arttext\&pid=S0080-62342017000100800\&lng=pt.

Humaniza, S. U. S. (2004). Política Nacional de Humanização: a humanização como eixo norteador das práticas de atenção e gestão em todas as instâncias do SUS/Ministério da Saúde, Secretaria Executiva, Núcleo Técnico da Política Nacional de Humanização. Brasília: Ministério da Saúde.

Instituto Nacional de Câncer. (2020) incidência de câncer no Brasil. Rio de janeiro, RJ, Brasil. https://www.inca.gov.br/estimativa/estado-capital/brasil.

King, I. M. (1981). A theory for nursing systems, concepts, process.

Leão, C. F., Coelho, M. E. D. S., Siqueira, A. O., Rosa, B. A. D. A., \& Neder, P. R. B. (2018). O uso do whatsapp na relação médico-paciente. Revista Bioética, 26(3), 412-419. http://dx.doi.org/10.1590/1983-80422018263261. 
Research, Society and Development, v. 10, n. 4, e1710413854, 2021

(CC BY 4.0) | ISSN 2525-3409 | DOI: http://dx.doi.org/10.33448/rsd-v10i4.13854

Lima, I. C. V. D., Galvão, M. T. G., Pedrosa, S. C., Cunha, G. H. D., \& Costa, A. K. B. (2018). Uso do aplicativo Whatsapp no acompanhamento em saúde de pessoas com HIV: uma análise temática. Escola Anna Nery, 22(3). https://doi.org/10.1590/2177-9465-ean-2017-0429.

Pereira A. S. et al. (2018). Metodologia da pesquisa científica. UFSM. https://repositorio.ufsm.br/bitstream/handle/1/15824/Lic_Computacao_MetodologiaPesquisa-Cientifica.pdf?sequence=1.

Pereira, D. A., Costa, N. M. D. S. C., Sousa, A. L. L., Jardim, P. C. B. V., \& Zanini, C. R. D. O. (2012). The effect of educational intervention on the disease knowledge of diabetes mellitus patients. Revista Latino-Americana de Enfermagem, 20(3), 478-485.

Pereira, J. S. P. (2018). A Influência da Orientação da Enfermagem antes da Alta Hospitalar no Prognóstico do Paciente. Amazônia Science \& Healt. 6(4).

Pinto, A. C. S., Scopacasa, L. F., Bezerra, L. L. D. A. L., Pedrosa, J. V., \& Pinheiro, P. N. D. C. (2017). Uso de tecnologias da informação e comunicação na educação em saúde de adolescentes: revisão integrativa. Rev. enferm. UFPE on line, 634-644.

Ressler, P., \& Glazer, G. (2010). Legislative: Nursing's engagement in health policy and healthcare through social media. OJIN: The Online Journal of Issues in Nursing, 16(1), 1-5.

Santos, Z. M. D. S. A., \& Lima, H. D. P. (2008). Tecnologia educativa em saúde na prevenção da hipertensão arterial em trabalhadores: análise das mudanças no estilo de vida. Texto \& Contexto-Enfermagem, 17(1), 90-97.

Selhorst, I. S. de B., Bub, M. B. C., \& Girondi, J. B. R. (2014). Protocolo de acolhimento e atenção para usuários submetidos a endoscopia digestiva alta e seus acompanhantes. Revista Brasileira de Enfermagem 67(4), 575-580. https://doi.org/10.1590/0034-7167.2014670412.

Selhorst, I. S. de B., Bub, M. B. C., \& Girondi, J. B. R. (2015). Usuário submetido à endoscopia digestiva alta e seu acompanhante: Perfil e expectativas. Enfermagem em Foco, 4(3/4), 207-210. https://doi.org/10.21675/2357-707X.2013.v4.n3/4.554.

Silva, D. M. D. L., Carreiro, F. D. A., \& Mello, R. (2017). Tecnologias educacionais na assistência de enfermagem em educação em saúde: revisão integrativa. Rev. enferm. UFPE on line, 1044-1051.

Silva, M. G. (2010). Enfermagem em endoscopia: digestiva e respiratória. Atheneu.

Silva, R. D. S. (2013). Exame endoscopia digestiva alta: percepções dos pacientes submetidos ao exame e contribuição de enfermagem.

Silva, S. S. F. da, Monteiro, J. de A. S., Silva, L. R. da, Francisco, M. R., Brasil, Y. Z., \& Paula, D. G. de. (2020). Produções tecnológicas desenvolvidas por Enfermagem: revisão sistemática. Research, Society and Development, 9(8), e224985721. https://doi.org/10.33448/rsd-v9i8.5721

Souza, M. T. D., Silva, M. D. D., \& Carvalho, R. D. (2010). Revisão integrativa: o que é e como fazer. Einstein, 8(1), 102-106.

Thomas, L. S., \& Fontana, R. T. (2020). Uso das Tecnologias de Informação e Comunicação como meio educacional na saúde: revisão integrativa. Research, Society and Development, 9(10), e9869109321. https://doi.org/10.33448/rsd-v9i10.9321

Trentini, M., Paim, L., \& Silva, D. M. G. V. (2014). Pesquisa convergente assistencial: delineamento provocador de mudanças nas práticas de saúde. Porto Alegre: Moriá, 175, 175p. 